\title{
El exilio y la política de la transición. Una reflexión sobre la continuidad de la izquierda parlamentaria ${ }^{1}$
}

\author{
Abdón Mateos
}

\begin{abstract}
RESUMEN
El autor propone la tesis de continuidad respecto al exilio en la trayectoria de la izquierda parlamentaria durante la transición. No hubo ruptura con el exilio y, por tanto,

refundación del PSOE y del PCE debido a la presencia cualificada de históricos de la guerra civil y de miembros de la segunda generación del exilio/primera clandestinidad en los circulos de poder interno de ambos partidos. Pero, sobre todo, no hubo refundación del PSOE tras Suresnes por la continuidad de aspectos claves de su política y por el peso de la conciencia histórica del franquismo en

la cultura política de los socialistas.
\end{abstract}

PALABRAS CLAVE Socialismo. PSOE. PCE. Franquismo. Transición. Elites. Cultura política
ABSTRACT

The author aims to show that the evolution of tehe Parliamnetary left wing is ultimately roots on the exile. PSOE anf PCE never broke their links with the exile and therefore were never refounded, due to the leading presence of persons who played a role in the civil war as well as of members of the second generation of the exile and the first underground movements in the core of both parties. Over all, the PSOE was never refounded after Suresnes as the key features of its politics remaied unchanged and historical conscience of francoism played a decisive part in the Socialist political culture.

KEY WORDS

Socialism. PSOE. PCE. Francoism. Transition. Elites. Political Culture.

Conterencia pronunciada en el curso organizado por la Fundación Pablo Iglesias, en colaboración con el departamento de Historia Contemporánea de la UNED, Las izquierdas españolas durante el siglo xx. Madrid, febrero-mayo 1999. 
Los dos términos aquí reunidos, exilio y transición, nos remiten a la historia de un malentendido, a una historia de falsas percepciones, imágenes e incomprensiones mutuas entre la España peregrina y la que padecia a Franco en el interior del país. La bandera de la nueva generación antifranquista surgida desde los sucesos universitarios y las protestas obreras de 1956 era la rotunda afirmación de que la guerra civil había acabado. Una guerra civil recibida por el nuevo antifranquismo con los sentimientos contradictorios de subyugamiento e indiferencia. Este era el aglutinante generacional de los nuevos antifranquistas nacidos con posterioridad a la contienda.

A esta afirmación se unía la visión de los principales partidos de la izquierda como organizaciones enfermas de revisionismo, de reformismo. El partido socialista obrero y el partido comunista no sólo estarían anclados en el pasado de la guerra sino que habían olvidado el lenguaje de la revolución, de la lucha no sólo contra la dictadura de Franco sino contra el capitalismo.

Como decía un representante de las nuevas generaciones antifranquistas, el militante del Frente de Liberación Popular, el felipe Luciano Rincón, los militantes de la nueva izquierda luchaban contra la triple dictadura de Franco, del Movimiento y del capital. Los nuevos socialistas se verian encajonados entre la espada del General y la pared de la Ejecutiva de Toulouse ${ }^{2}$.

Por su lado, los refugiados miraban con recelo a los intelectuales y profesionales de la nueva oposición formados durante el franquismo. A un origen mayoritariamente vinculado a los hijos de los vencedores se unía la idea de la deformación de las conciencias que habría traído consigo el primer franquismo.

Cuando en el verano de 1969 el escritor socialista Max Aub regresó por vez primera a España se encontró con una nueva sociedad recién salida de la era del silencio o del miedo, vivida durante el primer franquismo, pero que no quería saber nada del pasado. Nadie le preguntaba por el pasado de los años treinta y menos por la guerra civil. El mismo Aub había certificado el final del exilio, al menos desde un punto de vista intelectual, desde $1964{ }^{3}$. Por otro lado, no había dejado de dolerle la actitud recelosa que le habia parecido encontrar entre los intelectuales antifranquistas hacia los exiliados que regresaban a España. Existía la idea de un exilio

Un ejemplo de ensayo político del nuevo antifranquismo en la obra de Ramirez, Luis, Nuestros primeros 25 años, París, Ruedo Ibérico, 1964.

Véase sus Diarios (Barcelona, Albia, 1998) con una introducción de Manuel Aznar. También las amargas reflexiones de su Gallina Ciega (México, 1972). 
dorado que, además, traía asociado el recuerdo de la guerra civil, frente a la exaltación del exilio interior y la resistencia clandestina antifranquista. A esta misma conciencia habian llegado en fechas similares intelectuales del primer o del segundo exilio como Francisco Ayala o Juan Goytisolo. Una nueva sociedad emergía frente a la sociedad anómica y silenciada de posguerra percibida poco antes de las huelgas de 1962 por observadores foráneos como Rossana Rossanda o representantes del nuevo antifranquismo. Según Luciano Rincón:

"La española es la dictadura de la indiferencia. Frente a la del miedo o de la denuncia - que es la de los primeros años- la del bostezo ante lo nacional, ante lo colectivo, ante lo de todos" ${ }^{4}$.

El destino por excelencia de la imagen sobre el exilio político e intelectual era México ${ }^{5}$. No tanto por el balance cuantitativo, claramente inferior al escenario francés, sino por esa idea del bienestar de los exiliados, anclaje en el pasado de la guerra y alejamiento de las nuevas realidades españolas.

Algo de verdad tenía, sin duda, esa imagen. Durante los primeros años setenta socialistas y comunistas sufrieron escisiones protagonizadas por personajes históricos cuyas experiencias políticas eran anteriores a la segunda república. Mientras que en Europa las secciones del exilio político de los partidos de izquierda se habían dividido, en México la práctica totalidad de la militancia se habia identificado con las fracciones vinculadas con el pasado. En clave de broma se dijo que los militantes mexicanos más que históricos eran prehistóricos. Algo que no era ajeno a la fijación de los mitos de la España republicana y de la solidaridad antifascista del presidente Cárdenas durante la guerra civil en el México nacional-revolucionario ${ }^{6}$.

EI PSOE se había dividido en 1971-1972 en dos mitades en el exilio debido, en gran medida, al debate sobre la unidad de acción con los comunistas. No en vano el aglutinante de posguerra de los socialistas había sido el rechazo hacia la colaboración con el PCE que habian mantenido durante el período del Frente Popular y que habia llegado al punto de la creación de comité de enlace y proyectos de unificación. El rechazo hacia esa colaboración había permitido la superación de las tendencias y de las

\footnotetext{
Ramirez, Luis, op. cit., pág. 30; y Rossanda, Rossana, Un viaje inútil, Barcelona, 1984.

Véase la interesante reflexión del hijo de exiliado, Rafael SEGOViA, "La dificil socialización del exilio", en Los refugiados españoles y la cultura mexicana, Madrid, Residencia de Estudiantes, 1998.

Véase PowelL. Thomas, Mexico and the Spanish Civil War, Alburquerque, U. New Texas, 1981.
} 
líneas de fractura que habían recorrido al socialismo español en torno a las figuras de Julián Besteiro, Francisco Largo Caballero e Indalecio Prieto. Sin embargo, este aglutinamiento en torno a la tradición de Pablo Iglesias no se resolvió del todo en México pues allí tendieron a consolidarse la fracturas de la guerra civil. Ese estancamiento en el pasado en el caso de la emigración socialista en México se vio reforzado por el hecho de que el centro de gravedad de la política del exilio se desplazara con claridad desde 1945 a Francia.

Sin duda existió una especie de avivamiento de los fantasmas del pasado, del temor a que se volviera a producir como durante la contienda, una entrega de buena parte de la familia socialista a los comunistas españoles. El hecho de que uno de los principales dirigentes renovadores del interior, Enrique Múgica, - presente en las comisiones ejecutivas desde 1967-, hubiese militado hasta 1962 en el PCE no hizo sino alimentar el recelo de Rodolfo Llopis y de los dirigentes socialistas en México, Víctor Salazar y Ovidio Salcedo. Mientras que los dirigentes renovadores tendían a realzar la identidad marxista del partido socialista como instrumento para neutralizar la emergencia de nuevas formaciones de la izquierda socialista y competir por la hegemonía con el PCE, algunos históricos del exilio asimilaban la doctrina marxista no sólo con el comunismo sino con el mismo imperio soviético.

En el caso de los comunistas el relegamiento de las conmemoraciones de la guerra civil, por ejemplo, la victoria electoral del Frente Popular en febrero de 1936 o la defensa de Madrid, así como el silenciamiento de la experiencia guerrillera hasta 1952, habían tenido tanta o más importancia en el desenlace de las escisiones prosoviéticas que la formulación de la idea eurocomunista. Juan Ambou, miembro del Consejo interprovincial de Asturias y León durante la guerra y exiliado en México, escribió un libro a medio camino entre las memorias y el ensayo político, Los comunistas en la resistencia nacional republicana, en el que traslucia este malestar por esa amputación del pasado dentro de la nueva política de la memoria del PCE.

Una gran mayoría de la sección mexicana del PCE fue contraria al eurocomunismo como ha destacado e! filósofo marxista Adolfo Sánchez Vázquez ${ }^{7}$. Incluso entre los seguidores de la línea eurocomunista, el anclaje ideológio en la tradición leninista era muy acusado. Por ejemplo, el intelectual comunista transterrado en México, Wenceslao Roces, valoraba de esta forma el triunfo electoral de los socialistas portugueses en 1975:

Véase Recuerdos y reflexiones del exilio, México, Grijalbo, 1997. 
«...las elecciones no son siempre reales. No debemos juzgar las elecciones de una manera mecánica, al margen de las condiciones históricas 0 , según, LENIN, de la realidad social ${ }^{8}$.»

El alejamiento respecto a la nueva sociedad española de las secciones de los partidos socialista y comunista en México se vio acrecentado por la práctica inexistencia de una segunda generación del exilio político. En realidad, desde el agotamiento del Movimiento 59, - una plataforma suprapartidaria y de solidaridad con la oposición clandestina constituida en México en 1959-, tras las huelgas de 1962-1963, esa segunda generación del exilio terminó integrándose plenamente en la sociedad de acogida. Elena Aub y Eulalio Ferrer, hijos de destacados socialistas, han rememorado esa frustrante experiencia ?

Ese distanciamiento respecto a la política del exilio de los refugiados en México no era algo nuevo pues desde el bienio germano-soviético entre 1939-1941 se había producido la primera oleada de abandonos de militancia y naturalizaciones como mexicanos. Intelectuales socialistas, algunos temporalmente filocomunistas, como Max Aub, Manuel Serra i Moret, José Gaos, Margarita Nelken, Aurora Arnaiz, José Comas o Anselmo Carretero Jiménez se habían desligado enseguida de una política del exilio en México recorrida por todo tipo de fraccionalismos.

Realizado este preámbulo, cabe adelantar que no voy a trazar un recorrido narrativo general a lo largo de la trayectoria de las izquierdas españolas entre el final de la guerra civil y 1982. La necesaria brevedad de este texto y la aparición reciente de monografías me excusan de ese cometido. Se trata mas bien de reflexionar sobre la influencia que las experiencias del exilio y su otra cara, la primera clandestinidad, tuvieron sobre la política de la izquierda parlamentaria durante la transición. Dado que el PSOE protagonizó la política del exilio, aunque hay que reconocer el predominio clandestino del PCE, y de la monarquía democrática, la mayor parte de las reflexiones se centraran en la historia de la familia socialista.

\section{GENERACIONES MILITANTES Y MODELO DE PARTIDO}

Las organizaciones socialistas fueron reconstituidas en 1944 tanto en España como en Francia. En el caso de Cataluña la constitución del

\footnotetext{
B Véase su testimonio en León-PORTIlla, Ascensión, España desde México. Testimonio de transterrados, México, FCE, 1978, pág. 364.

9 Veánse. Ferrer Rodriguez, Eulalio, Del diario de un publicista, México, Diana, 1993; y Aub, Elena, Historia del ME/59, México, INAH, 1992.
} 
Movimiento Socialista (MSC) se trató de una verdadera refundación del socialismo después de su desaparición tras la bolchevización de la formación unitaria surgida con la guerra civil (PSUC). El ascenso de Rodolfo Llopis a la secretaría general de PSOE suponía el relevo de una generación de líderes socialistas más veteranos como Francisco Largo Caballero o Indalecio Prieto.

El nuevo secretario general procedía de la corriente sindical del socialismo, de la línea radical caballerista, habiendo desempeñado la dirección general de Segunda Enseñanza durante el primer bienio republicano y la subsecretaría de Presidencia en el gobierno frentepopulista de Largo Caballero ${ }^{10}$. En 1947 presidió el último gobierno republicano en el exilio realmente representativo y con cierta influencia. Más adelante, en 1956, añadiría al liderazgo del partido el cargo de presidente de la UGT hasta 1971.

Un nuevo grupo dirigente en torno a los cincuenta años y con predominio de los antiguos radicales largocaballeristas se hacía con las riendas del PSOE y de la UGT en el momento del final de la segunda guerra mundial. Los dirigentes de las ejecutivas del período frentepopulista como Ramón Lamoneda, José Rodríguez Vega y Ramón González Peña quedaron marginados de ese aglutinamiento que rechazaba la experiencia de colaboración con los comunistas de los años del Frente Popular.

En el caso de los comunistas españoles el relevo de los dirigentes de la época de la guerra civil fue más tardía. La muerte de José Díaz en 1942 y su sustitución por Dolores Ibárruri, Pasionaria, no trajo consigo un verdadero relevo del primer círculo de poder interno. No será hasta el relegamiento de Vicente Uribe en 1956 y la elección de Santiago Carrillo a la secretaría general del PCE en 1960 cuando se pueda hablar de un cierto giro interno asociado a la formulación de la política de reconciliación nacional. No obstante, hay que recordar que Comorera fue sustituido por un histórico de la guerra civil, el antiguo ministro de Negrín, Josep Moix, no ascendiendo a la secretaría general Gregorio López Raimundo hasta 1965.

El caso de los comunistas catalanes resulta especialmente interesante para examinar el alcance del giro de 1956. Aunque una reciente monografía de Carme Cebrián ${ }^{11}$ ha insistido en la idea de refundación del PSUC en 1956, fecha de la celebración del primer congreso durante la dictadura

10 Una biografía reciente, especialmente interesante hasta 1947, fecha de la caida de su gobierno en el exilio, en VARgas, Bruno, Rodolfo Llopis. Una biografía política, Barcelona, Planeta, 1999.

CEBrian, Carme, Estimat PSUC, Barcelona, Empuries, 1996. 
de Franco, la presencia de Moix en la secretaria y la permanencia en el primer círculo de poder interno de otros dirigentes como Serradell, Ardiaca o Núñez hasta bien entrados los años sesenta hace dudar de la profundidad de esa renovación.

A mi juicio, la superación del estalinismo es un proceso ligado no a la formulación de la política de reconciliación nacional sino a la inserción de los comunistas españoles en los movimientos sociales emergentes sobre todo a partir de 1962. Será esta implantación lo que llevará a la formación de una cultura política democrática.

La verdadera renovación de los órganos dirigentes, más por la base que por la cúspide, comenzará realmente con la ampliación del comité central del PCE en agosto de 1970 y, sobre todo, del VIII Congreso de 1972. Este es el momento no sólo de la ruptura con los prosoviéticos y de los inicios del eurocomunismo sino del ascenso a puestos dirigentes de miembros de la nueva generación antifranquista de los años sesenta y no sólo de los pertenecientes a la generación de los niños de la guerra civil.

Mas de dos tercios de los delegados a los primeros congresos de la democracia del PCE (1978) y del PSUC (1977) se habian incorporado a la militancia durante los años setenta.

En el caso de la familia socialista se produjo la formación de un nuevo equipo dirigente desde 1970, momento en el que los dirigentes del interior pasaron a ser unilateralmente mayoritarios en el seno de la dirección compartida. Un modelo de dirección compartida, con residencia de las Ejecutivas en Toulouse establecido en 1958 tras la desarticulación de la organización clandestina de la etapa de Antonio Amat. Desarticulación que no fue completa, aunque hubo una nueva redada general en agosto de 1960, y cuya composición generacional era variada pese al predominio de los militantes que habían hecho la guerra civil. Estas desarticulaciones generales no se deben interpretar como una mera continuación de las que destrozaron a las ejecutivas clandestinas de la inmediata posguerra (19451953) no sólo por la plural composición generacional de la militancia implicada sino la moderación de las penas.

La organización clandestina sufrió a partir de entonces una década de difícil existencia como organización centralizada en buena medida a causa de la propia decisión de los secretarios generales, Rodolfo Llopis y Pascual Tomás. Sin embargo, resulta excesivo caracterizar al PSOE y a la UGT a partir de 1958 como organizaciones exclusivamente del exilio. La residencia de la dirección y el predominio dirigente del exilio en el caso de otros partidos históricos como el PCE y el PNV fue igual o mayor que en el caso socialista. Este modelo de dirección compartida 
exterior-interior se mantuvo hasta octubre de 1974 para el PSOE y abril de 1976 para el sindicato socialista.

Desde 1970 lo que se produjo en el seno de la familia socialista fue el predominio de la organización clandestina en el núcleo dirigente. Además hubo un ascenso de un grupo de militantes formados en lo que se puede denominar segunda generación del exilio, en su mayor parte niños durante la guerra civil. Esta noción de segunda generación del exilio resulta decisiva para comprender la transición interna de los socialistas españoles durante los años setenta. Un segunda generación del exilio formada no sólo con los hijos de los refugiados de 1939 sino con los huidos de España desde la primera clandestinidad de posguerra y la emigración económica a partir de los años cincuenta.

Mas que ruptura con el exilio to que hubo fue un ascenso de esa segunda generación del exilio en parte formada con miembros de la primera clandestinidad. Con la excepción de Felipe González y, desde octubre de 1972. Alfonso Guerra, todos los miembros de la ejecutiva de la UGT tenían experiencia personal de la guerra civil, el exilio o la primera clandestinidad. Los representantes de las nuevas generaciones antifranquistas de 1956 y 1968 presentes en la dirección de UGT entre 1971 y 1976 no pasaron de un $20 \%$ del total. Dirigentes socialistas como Nicolás Redondo, Enrique Múgica, Pablo Castellano, Marcelo García, Agustín González o Joaquín Jou habían sido niños de la guerra civil. Otros dirigentes como Jesús Mancho, Paulino Barrabés, Manuel Garnacho, Carmen Garcia Bloise, Carlos Pardo o Manuel Simón pertenecían a la segunda generación del exilio hubiesen nacido antes o después de la guerra civil.

En suma, no puede interpretarse en términos de ruptura con el exilio y la primera clandestinidad la renovación generacional acaecida en las organizaciones socialistas y, en especial, la UGT desde 1971. En todo caso, si puede decirse que desde los primeros años setenta hubo una glorificación de la experiencia de clandestinidad de posguerra sobre la memoria de la guerra civil y la emigración republicana de 1939. No deja de ser significativo el ascenso a puestos dirigentes en el exilio de militantes con experiencia de la primera clandestinidad como Antonio García Duarte, Juan Iglesias (presentes en la dirección de UGT desde 1962), José Mata, Ramón Porqueras o Máximo Rodríguez ${ }^{12}$.

12 Anteriormente habian formado parte de las Ejecutivas del exilio los antiguos dirigentes clandestinos Antonio Pérez y Antonio Trigo. 
La comisión ejecutiva elegida en su totalidad por primera vez en el XII Congreso de UGT en Toulouse en agosto de 1973 conservó la proporción de cinco dirigentes en el exilio frente a los nueve del interior pero hay que tener en cuenta que Agustín González y Jesús Mancho tenian experiencia del exilio a través de años de emigración económica. A este equipo dirigente del interior se sumaron desde 1975 los miembros de la segunda generación del exilio Manuel Simón y Manuel Garnacho. Por tanto, entre 1973 y 1976 la mitad de los miembros de la ejecutiva del sindicato socialista tenían experiencia del primer o segundo exilio.

Si bien es cierto que la ejecutiva salida del Congreso del PSOE en Suresnes, encabezada por Felipe González, como primer secretario, reducía la presencia de la primera clandestinidad y del exilio a una cuarta parte del total de los dirigentes (Nicolás Redondo, Agustín González y Juan Iglesias) hay que tener en cuenta el hecho de la imbricación por aquel entonces de los equipos dirigentes del partido y del sindicato. Si consideramos el conjunto de los miembros de ambas ejecutivas hasta 1977, todavia bastantes comunes, cerca de la mitad había nacido antes de la guerra civil y alguno más en el exilio. De este modo, difícilmente se puede hablar de una ruptura con el exilio y, por tanto, de refundación generacional del socialismo ${ }^{13}$.

Además si tenemos en cuenta no sólo el primer circulo de poder interno, ampliando el análisis generacional a los candidatos y parlamentarios de 1977, la tesis de ruptura con el exilio resulta también matizable. De este modo, se puede calcular que un $25 \%$ de los parlamentarios socialistas pertenecian a generaciones militantes anteriores a las surgidas con el nuevo antifranquismo de 1956. De estos treinta parlamentarios socialistas aproximadamente la mitad habian tenido una experiencia del primer o segundo exilio ${ }^{14}$ Posteriormente, serían parlamentarios los exiliados José Prat y Francisco López Real. Por otro lado, hay que tener en cuenta que una parte notable de la primera y segunda generación del exilio estaban integrados en las sociedades de acogida y/o habian perdido la nacionalidad española lo que les impedía una presencia en las candidaturas.

Hubo una presencia destacada del exilio y de la primera clandestinidad en las candidaturas de al menos ocho provincias ${ }^{15}$. Una geografía que

\footnotetext{
13 Esta tesis en JULIA, Santos, Los socialistas en la politica espariola, 1879-1982, Madrid. Taurus, 1997.

${ }_{14}$ Entre ellos he identificado a José Antoio Aguiriano, Antonio Carasol, Rafael Fernández, Manuel Diaz-Marta, Antonio García Duarte, Sócrates Gómez, Fabián Ramos, Máximo Rodriguez, Juan Iglesias, Lino Calle, Carmen García-Bloise, Moll Marqués, Revilla, Subirats.

15 Madrid, Vizcaya, Asturias, Jaén, Málaga, Barcelona, Alava y Valencia.
} 
coincidía en términos generales con las de las federaciones más sólidas durante la clandestinidad con excepción de Guipúzcoa, Alicante y Santander, debido a la escisión de los históricos en estas dos últimas. En el emblemático caso de la capital, la candidatura tenía en los primeros ocho puestos a tres exiliados (Sócrates Gómez, Máximo Rodríguez y Carmen Garcia Bloise) además de dos dirigentes de la primera clandestinidad como Manuel Turrión y Julia Vigre.

Es cierto que en el caso de los comunistas la presencia del exilio y de la primera clandestinidad en las candidaturas fue mucho más destacado. Nada menos que trece cabezas de lista provinciales habían tenido experiencia de exilio ${ }^{16}$. Otros parlamentarios como Wenceslao Roces o Marcelino Camacho habian tenido también experiencia del exilio. Se puede calcular que más de la mitad de los cabezas de lista del PCE habian nacido antes de la guerra civil, un porcentaje que por lo menos doblaba a los de las candidaturas del PSOE.

Tras el inesperado fracaso electoral de los comunistas durante las elecciones de 1977 hubo un tímido debate interno en el seno de los órganos de dirección en torno a la excesiva presencia electoral de los históricos de la guerra civil y del primer franquismo. El debate fue mal cerrado pues si bien era cierto esa especial visibilidad de personajes comunistas que recordabar un pasado que interesaba silenciar ${ }^{17}$, el caso de Cataluña contradecía esa valoración. En efecto, el PSUC había obtenido los mejores resultados, en torno a un $20 \%$, cuando tres de las candidaturas estaban encabezadas por personajes del exilio y de la primera clandestinidad (López Raimundo, Solé Barbera y Ardiaca).

\section{EN TORNO A LA IDEOLOGÍA Y LA CULTURA POLÍTICA}

Otro de los rasgos de continuidad con la experiencia del exilio fue sin duda la acción política. Tanto en las políticas de unidad socialista como la sindical, al menos durante la transición, o la de relaciones con otras fuerzas hubo destacados componentes de continuidad.

La idea de unidad socialista tanto en el exilio o la transición tuvo a las siglas históricas como algo irrenunciable. Fue rechazada la idea de una

16 Ibárruri, Carrillo, Azcárate, Alberti, Tomás García, Gallego, Romero Marín, José Maria González Jérez, Santiago Álvarez, Ramón Ormazabal, López Raimundo, Ardiaca, Solé Barbera.

17 Sobre la memoria histórica de la guerra civil durante la transición hay que destacar el pio nero estudio de Paloma Agullar, Memoria y oivido de la guerra civil, Madrid, Alianza, 1996. 
federación de partidos socialistas, adoptándose un modelo de partido federal tras el pionero acuerdo con el Partido Socialista de Cataluña, formación surgida a partir del histórico Movimiento Socialista (1945). La unidad socialista culminó formalmente en 1978 aunque hasta que el acceso del PSOE al gobierno pervivieron los grupos de origen como corrientes de opinión más que como tendencias organizadas. Este fue sobre todo el caso de las federaciones y partidos de Madrid, Cataluña y el País Valenciano donde las tradiciones históricas del socialismo eran más plurales ${ }^{18}$.

Ya he destacado antes como el rechazo a las relaciones bilaterales con el PCE fue otro de los rasgos de continuidad con la política del exilio. Durante la transición interna de los socialistas durante los años setenta el aglutinante ya no era tanto el rechazo hacia los comunistas como la referencia de la experiencia de la socialdemocracia europea pero hubo una clara idea de lucha por la hegemonía, o como lo ha caracterizado Juliá, de cooperación competitiva. Desde luego, persistió la idea de una futura acción política en democracia autónoma respecto a otras formaciones políticas. En 1947 se había puesto fin a una estrategia de colaboración política, abierta cuarenta años antes, con los partidos republicanos de izquierda, dado que se pensaba que no iban a representar nada en el futuro. La idea de representación electoral directa de los intereses de las clases medias no fue algo de la transición sino que ese planteamiento existió al menos desde los años cincuenta.

Estos componentes de la política socialista fueron más significativos que el hecho de que se abandonará la fórmula de transición a la democracia elaborada al final de la década de los cuarenta. Es cierto que tras la constitución de la Plataforma de Convergencia Democrática en 1975 el PSOE abandonó la reivindicación de un gobierno provisional sin signo institucional definido que consultara a los españoles sobre la forma definitiva de Estado, algo que también hizo el PCE poco antes de la constitución al comienzo de 1976 de la Platajunta, pero esto no resulta suficiente para interpretar este giro como una ruptura con la política del exilio.

Aunque el PSOE continuaba siendo republicano, tanto en la época de Indalecio Prieto como de Rodolfo Llopis se habían hecho esfuerzos de acuerdo con formaciones monárquicas y accidentalistas en torno a una fórmula intermedia de transición democrática. En diversos momentos los

18 Los casos de estas regiones han sido estudiados por Richard GILLESPIE, Historia del PSOE (Madrid, 1991); Benito Sanz, Los socialistas en el País Valenciano (Valencia, 1988); Gabriel CoLOMER, Els Partit del Socialistes de Catalunya (Barcelona, 1989); y Fernando MILLÁN, Del PSOE al PSPV (Valencia, 1991). 
socialistas habían dejado claro que si se daba ese tipo de transición votarían por la instauración de una república pero también habían reconocido públicamente las ventajas de una monarquía constitucional frente a una dictadura. Sin carácter oficial y público, además, habían expresado su disposición a colaborar con una monarquía que restaurara las libertades.

Los principales dirigentes socialistas, Rodolfo Llopis, Indalecio Prieto, Trifón Gómez y Pascual Tomás, conocieron muy de cerca la evolución del discurso y acción político-sindical del socialismo europeo. Esto no significó, necesariamente, una identificación con los postulados de todos los partidos y sindicatos, pues la trayectoria fue muy diferente en cada uno de los paises. No obstante, existieron unos rasgos comunes que los dirigentes del socialismo español compartieron plenamente. Uno de ellos era la recuperación del valor de la democracia, de la colaboración con los partidos «burgueses» si era necesario para estabilizar el sistema político frente a reaccionarios y comunistas. En el discurso político de Llopis tuvo un papel central la reflexión sobre la futura transición hacia la democracia. Una reflexión que se alargó por más de treinta años, sin ver coronados con el éxito o la mera aproximación respecto a la forma en que realmente se produjo desde 1975.

El viejo internacionalismo fue sustituido en la Europa de la posguerra por una esperanza en la construcción de un orden europeo supranacional, democrático y socialista. Esta evolución fue sobre todo cosa de los socialistas franceses, belgas, italianos y españoles, -el grupo latino-, mientras que escandinavos, británicos y, en un principio, alemanes, hicieron mucho mayor hincapié, de acuerdo a sus responsabilidades gubernamentales, en soluciones nacionales. No obstante, los socialistas y ugetistas españoles insistieron siempre con ocasión de declaraciones y estatutos de las nuevas organizaciones internacionales socialistas y sindicales en los viejos principios del internacionalismo y de la lucha de clases.

El europeismo de los líderes del socialismo español fue mucho más pronunciado que el occidentalismo, sobre todo por la profunda decepción sufrida con los Estados Unidos en los años cincuenta. La gibraltarización de España tras el pacto de 1953, como decía Prieto, fue el origen de una nueva seña de identidad neutralista y antiimperialista que, si bien fue minoritaria durante los años cincuenta y sesenta, terminó caracterizando a la ideología socialista durante la siguiente década.

Los dirigentes socialistas nunca asumieron el «revisionismo» de británicos y alemanes en la actitud frente al sistema capitalista. Eran exiliados, por lo que no podian dedicar una especial atención a los problemas económicos españoles y a la integración europea e internacional. Entre los socialistas exiliados persistieron aciitudes inequivocamente anticapitalistas. Lo que 
ocurrió fue que la centralidad política del "problema español» hizo perder importancia inmediata a la reflexión económica. El europeísmo estuvo siempre acompañado de una crítica paralela del capitalismo. La unidad europea sería, pues, una manera de resolver el problema obrero, de suprimir las desigualdades sociales y de lograr la construcción de un nuevo orden social basado en la paz, la fraternidad solidaria, la libertad y la justicia.

De todas maneras, los socialistas de posguerra acogieron con verdadera simpatía las experiencias de gobierno de laboristas y socialdemócratas. Por ejemplo, la ejecutiva ugetista, con ocasión de su $\vee$ Congreso en el exilio en noviembre de 1953, valoraba estas experiencias de gobierno socialista durante la posguerra como una prueba de como puede la clase trabajadora construir con respeto para la vida del hombre los fundamentos de la sociedad socialista.

En cambio, la valoración de la URSS y los partidos comunistas era totalmente negativa:

«Podrá el comunismo enarbolar como bandera para sus propagandas los errores de las democracias para con la verdadera España. Sin embargo repetimos - la nación más culpable - hoy como ayer- de que sigamos sufriendo el dolor del destierro unos, y las crueles sevicias de Franco otros, es la Rusia soviética, que tiene a su servicio el comunismo internacional» ${ }^{19}$.

El régimen soviético era equiparado al fascismo dentro de una común interpretación como sistemas totalitarios. El moderado Albar, director de El Socialista, afirmaba, en un artículo titulado Socialismo contra comunismo:

«El socialismo debe ser el guardián de la democracia mundial frente a un capitalismo que atenta contra ella cuando asi conviene a sus intereses inmediatos, y un comunismo que no es más que una versión del fascismo con etiqueta marxista” 20 .

La mayoría de los socialistas exiliados intentaron conjugar marxismo y anticomunismo. Por ejemplo, el caballerista radical Arsenio Jimeno consideraba que el leninismo era una mezcla de bakouninismo, blanquismo y marxismo, cuyo resultado ha sido un capitalismo de Estado en período prolongado de acumulación primitiva en beneficio de una nueva clase, y de forma dictatorial ${ }^{21}$.

\footnotetext{
19 Memoria de la Ejecutiva al V Congreso de UGT, noviembre de 1953, pág. 38.

2 Albar, Manuel, Cartas, artículos y conferencias de un periodista español en México, MéxiCo, Imp. Modernas, 1958, pág. 159.

21 Archivo de UGT. Arsenio Jimeno a Víctor Salazar, 24. XI.1971.
} 
Un aspecto central de la reflexión de los dirigentes socialistas exiliados fue el papel central asignado al sindicalismo en la restauración de la democracia y en la construcción del socialismo. Incluso Indalecio Prieto, quien durante los primeros cuarenta había acusado a los sindicatos del desastre de la guerra civil y defendido su subordinación respecto al PSOE y un futuro estado democrático, sufrió una especie de conversión sindicalista.

En 1946 Prieto difundió un Esbozo de un programa de socialización que constituía un proyecto de socialismo municipal y cooperativista retomando ideas que décadas antes había difundido el marxista Julián Besteiro. Era un socialismo reformista, libertario, ajeno a la deificación del Estado de la socialdemocracia pero también lejano del socialismo liberal. Para el regeneracionista, demócrata radical y futuro vicepresidente de UGT el Estado, perezoso e incompetente, debería delegar en la administración local, sindicatos y cooperativas la gestión de servicios sociales y la explotación de la tierra u otros recursos naturales. Para Prieto únicamente la tierra y el subsuelo serian objeto de socialización rechazando, en una primera fase, la extensión de las nacionalizaciones a la banca $\circ$ la gran industria.

En definitiva, Don Inda destinaba a los sindicatos, preferiblemente tras la fusión de UGT y CNT, un papel central en la construcción del socialismo en democracia. En 1958 Prieto defendió la existencia de una segunda cámara corporativa, un Consejo Económico y Social, llegando a afirmar que acaso la estructura de una España futura se cimentara en los sindicatos obreros más que en los partidos políticos. Prieto llegaba a especular sobre que el futuro destino del Estado era su desaparición, en un momento en que el mundo de posguerra vivía todo lo contrario debido a las políticas de bienestar occidentales o la sovietización.

La convicción del papel central de los sindicatos y, en concreto UGT, en la reconstrucción de la democracia y del movimiento socialista era generalizada. Por ejemplo, Luis Araquistain en 1953 aventuraba que «el destino político de España depende del destino de la Unión General de Trabajadores (...). Si perdemos definitivamente nuestra organización sindical, y con ella al Partido Socialista a quien sustenta, habremos perdido la base más sólida de un estado y una nación libres en España» ${ }^{2}$. El proyecto de socialismo municipalista de Prieto fue, en gran medida, recogido en la revisión del Programa Mínimo de UGT aprobada en el IX Congreso en 1965.

22 Véase Araquistain, Luis, Sobre la guerra civil y en la emigración, Estudio preliminar de Javier Tusell, Madrid, Espasa-Calpe, 1983; y Prieto, Indalecio, Ante el futuro español, Toulouse, 1958. 
La UGT del exilio aprobaba un proyecto de socialismo civilista más que estatalista más cercano a Prieto y Besteiro que al último Largo Caballero, todavía defensor en 1945 de una línea socialista marxista. Una línea, sin embargo, equivalente a la tradición socialdemócrata de capitalismo atemperado por el Estado. Largo Caballero en su escrito Del capitalismo al socialismo. Proyecto de gobierno para España señalaba:

"Se trata, francamente, de iniciar la transformación del régimen capitalista individual de hoy, en España, en otro de Estado, donde todo sea propiedad nacional (...); período transitorio a la socialización de toda la economía y de la retribución del trabajo según las necesidades ${ }^{23}$."

De igual modo Rodolfo Llopis, todavía en 1949, reclamaba el regreso al marxismo y compartía las ilusiones de tercera vía frente a las primeras revisiones neosocialistas de partidos europeos. Llopis recordaba el compromiso de los socialistas españoles con el objetivo final de una revolución que no sería, sin embargo, el mero tránsito al socialismo desde el capitalismo de estado planificado. Mas a partir de la década de los cincuenta el mito de la revolución como acto desapareció en la práctica del discurso ideológico del PSOE y de UGT. Pese a la identificación de socialismo y libertades los socialistas no concebían todavía a la democracia como un fin en si mismo. En 1954 el moderado Manuel Albar señalaba que cla democracia burguesa ... (es) el instrumento mejor de que disponemos para acelerar y facilitar la transición, porque en ese trance está el mundo, del capitalismo al socialismo" ${ }^{24}$. Esto no suponía una minusvaloración de la democracia liberal pero los socialistas todavia creían en la existencia de un régimen de democracia superior, denominado democracia socialista o democracia obrera. En definitiva las organizaciones socialistas en el exilio se declaraban abiertamente anticapitalistas y marxistas pero, al mismo tiempo, defendían un tipo de proyecto socialista reformista y antiestatalista.

En realidad, el centro de la reflexión y del debate ideológico de los socialistas exiliados fue el modelo de transición futura a la democracia y el examen de las diversas políticas contra Franco. Durante el primer exilio se produjo una progresiva disolución del radicalismo de la línea caballerista. Por supuesto, no sobrevivió la idea de Largo Caballero de unidad orgánica

${ }_{23}$ Un análisis detallado del pensamiento politico del veterano lider ugetista tras la guerra civil en ARóstegui, Julio, Francisco Largo Caballero en el exilio. La última etapa de un líder obrero, Madrid, Fundación Largo Caballero, 1990.

24 Albar, Manuel, Tesis politica desde el punto de vista socialista, conferencia en el Ateneo Español, México, 12.XI.1954. Llopis, Rodolfo, Emigración, exilio y perspectivas del mañana, México-Paris, Tribuna, 1949. 
del marxismo español en el seno de las organizaciones socialistas imponiéndose, en cambio, como nuevo aglutinante el rechazo hacia los comunistas y regulándose el predominio político del partido sobre el sindicato. En torno al debate de las políticas contra Franco y el futuro modelo de transición democrática aparecieron algunas diferencias ideológicas y de cultura política. Por ejemplo, los caballeristas radicales insistieron siempre más en la unidad de acción, inclusc orgánica, con CNT desconfiando de las relaciones con los monárquicos y las nuevas formaciones centristas. Fueron, además, paradójicamente más fieles a la memoria de la segunda república que los prietistas y la mayoría directiva.

Desde un punto de vista internacional, los minoritarios radicales se mostraron partidarios de una tercera vía neutralista. Por ejemplo, Arsenio Jimeno defendió esta postura tras la firma del acuerdo entre España y Estados Unidos frente al amargado occidentalismo de Prieto y a la interpretación benévola que del mismo pacto hacía Luis Araquistain. Un neutralismo que, sin embargo, no era anticolonialista ni contrario al estado de Israel como más tarde defenderían las formaciones de la nueva izquierda.

No obstante, donde se reveló con más claridad la pervivencia de una cultura sindicalista fue en la discusión del modelo de transición democrática. Tanto los dirigentes caballeristas radicales como buena parte de los antiguos besteiristas creyeron encontrar al comienzo de los años cincuenta, con la superación franquista del aislamiento internacional, un hipotético campo para la reconstrucción del sindicato en España. Se trataba de un debate sobre una posible liberalización sindical en el seno del régimen de Franco. Es decir se suponía que los nuevos compromisos internacionales con Occidente del régimen franquista trajeran consigo algunas aperturas políticas. Una de ellas podría ser la concesión de una libertad sindical limitada. Esta reflexión enlazaba con otra que suponía que la acción de los sindicatos sería tolerada antes que la de los partidos políticos en el momento de la transición a la democracia. A los oídos de los socialistas españoles, desplazados varias veces a los Estados Unidos, habian llegado las alusiones que congresistas y sindicalistas norteamericanos habian hecho sobre la libertad sindical, de prensa y de cultos religiosos como contrapartida franquista a los pactos que se estaban negociando entre ambos países.

Desde el punto de vista de la cultura política fue todavía más significativo el posibilismo del besteirista Trifón Gómez y el caballerista Luis Araquistain, unido al de la organización clandestina dirigida por el metalúrgico Antonio Trigo, el tranviario Tomás Centeno y el ferroviario Antonio Hernández Vizcaíno, ante la hipótesis de una restauración de la monarquía. 
Una restauración que concediera a las organizaciones y, de manera especial, a la UGT, la posibilidad de reorganizarse aunque no conllevase la existencia de un régimen pleno de libertades. Este posibilismo revelaba la pervivencia de una cultura sindicalista, todavía no plenamente democrática, cuyos mejores exponentes en el exilio eran, en cambio, Indalecio Prieto y Rodolfo Llopis. Por el contrario, la cultura oportunista revolucionaria fue marginal en el seno del socialismo de posguerra reducida a individualidades como, por ejemplo, Antonio Amat o Julio Álvarez del Vayo.

Los refugiados socialistas en Francia intentaron con un éxito relativo preservar los valores morales y políticos tradicionales del socialismo anterior a la guerra civil, constituyendo una especie de legado que permitiera enlazar con el nuevo socialismo que surgiera en España una vez liquidada la dictadura franquista. Valores morales tradicionales del obrerismo español como la rectitud, la disciplina de "abajo a arriba", la solidaridad, el compañerismo, la abnegación, la lealtad y el respeto, el civismo, el desinterés y la ausencia de ambiciones políticas, fueron resaltados continuamente en la prensa y los Congresos.

En cambio, el tono renovadamente anticapitalista y autogestionario de las nuevas generaciones del interior y del exilio estaba asociado a unas vivencias mucho más directas de las luchas obreras, y a la competencia de los grupos comunistas e izquierdistas. Pero era sobre todo una diferencia de tono y de centralidad de temas. Los nuevos socialistas empezaron a pensar no sólo sobre como acabar con el franquismo sino, lo que era mucho más difícil y lejano, como hacer resurgir al socialismo en España. En este sentido, no debe extrañar que se pusiera el acento tanto en la crítica de la socialdemocracia como del comunismo.

Una de las principales innovaciones ideológicas durante la transición interna de los socialistas fue el federalismo. EI PSOE había sido históricamente un partido centralista. Sin embargo, en 1964 el Congreso del partido recuperó la fórmula de 1918 que defendía la idea de una Confederación Republicana de Nacionalidades Ibéricas. Con anterioridad, a lo largo del exilio, habian existido grupos socialistas minoritarios defensores del federalismo. Los más importantes fueron los socialistas catalanistas del MSC y el reunido en torno a la revista, publicada en México, Las Españas ${ }^{25}$. Uno de los animadores principales de la idea federal fue Anselmo Carretero Jiménez, presidente del PSOE en México durante la transición. En sus obras,

25 Una reciente aproximación a esta revista, tras los ensayos de Alicia ALTED y Francisco CAUDET, en Rojo, Gabriel y VALENDER, James, "Las Españas, de cara a España, 1946-1963", Boletín de la Institución Libre de Enseñanza, 27, 1997, págs. 63-71. 
por ejemplo, Las nacionalidades españolas o Los Pueblos de España, Carretero fue uno de los primeros defensores de la idea de España como nación de naciones. Una perspectiva que sin duda influyó intelectualmente en la creación del Estado de las autonomias.

La política de la memoria de los socialistas en el exilio recordó, en primer lugar, a la figura de Pablo Iglesias, desapareciendo la advocación de otros padres fundadores como García Quejido. Además de la presidencia simbólica de todos los actos socialistas, la personalidad del Abuelo, verdadero apóstol laico de los socialistas españoles, era conmemorada todos los años el 9 de diciembre, fecha de su muerte. En un segundo plano, como prueba de la desaparición de las tendencias de los años treinta pero también de la composición de la base socialista, se situaban las imágenes de Francisco Largo Caballero y Julián Besteiro. Continuaron conmemorándose los aniversarios del Primero de mayo, de la proclamación de la República el 14 de abril y, más esporádicamente, fueron recordados los aniversarios de la insurrección de octubre de 1934, de la huelga general de 1917 y del inicio de la guerra civil con la respuesta popular al alzamiento del 19 de julio de 1936. Por el contrario, a partir de la refundación las organizaciones en 1944 desapareció la celebración de la victoria electoral del Frente Popular que, en cambio, había conmemorado en México la ejecutiva de UGT presidida por González Peña. Estas conmemoraciones, extendidas en ocasiores hacia personalidades y acontecimientos de otros países, nunca tuvieron un componente de análisis histórico crítico.

Por lo que se refiere a la conmemoración de los mártires de la represión, en 1948 el sentimental Indalecio Prieto tuvo la iniciativa de elaborar un libro de Muertes ejemplares que diese testimonio del terror franquista. Los ejemplos que simbolizaban a todos ellos fueron sobre todo Ricardo Zabalza, Julián Zugazagoitia y Francisco Cruz Salido, fusilados en 1940. A este martirologio se unió el caso de Tomás Centeno, presidente de las organizaciones en la clandestinidad fallecido en manos de la policía en 1953. Hubo también una exaltación de dirıgentes clandestinos presos durante un período muy prolongado, más de quince años, como Eduardo Villegas y Ramón Rubial. No obstante, la cultura política de los socialistas nunca fue muy propensa a la exaltación de héroes y a la creación mártires por una mezcla de pudor y una actitud ética contraria a los sacrificios excesivos de los militantes.

La memoria histórica colectiva trató de disociarse de la experiencia de la guerra civil, rectificada por el golpe del Consejo de Defensa en la que habian participado activamerite dirigentes del exilio como Pascual Tomás, Wenceslao Carrillo o Trifón Gómez. Un Consejo de Defensa, sostenido 
por buena parte de los ugetistas socialistas, que lejos de ser una iniciativa de traición al Frente Popular y de claudicación ante Franco, habría rectificado el rumbo de un sindicato, que entonces celebraba su cincuentenario, para volver a sus orígenes. Ese final rectificador de la guerra civil y de retorno a los orígenes del sindicato sería recordado durante los primeros Congresos del PSOE y de la UGT en el exilio. El nuevo aglutinante fue, pues, el rechazo de la experiencia de colaboración orgánica con los comunistas durante la guerra civil y el retorno a la tradición de un sindicato estrechamente unido al partido.

En definitiva, la política de la memoria socialista y ugetista jugó un papel decisivo durante los primeros tiempos transcurridos desde la refundación en el exilio. Como han puesto de manifiesto los dirigentes de la segunda generación del exilio, los hermanos Martínez Cobo, la constante repetición de los homenajes a los líderes del pasado era un claro recordatorio de la legitimidad del Partido frente al pleito mantenido en los primeros años de la posguerra por Negrín, Lamoneda y González Peña. (...). Lo que primero podía interpretarse como una respuesta defensiva se convirtió luego, alejado el primer peligro, en una tradición que cubría otra función: reagrupar, unir, fortalecer en comunes recuerdos al exilio socialista ofreciendo a cambio de una patria cada vez más lejana un historial como marco de vida ${ }^{26}$.

La competencia frente a los disidentes, en el partido hasta 1948 y en UGT hasta 1950 , así como la necesidad de reforzar los aglutinantes que habian permitido la refundación de 1944 , otorgó un papel decisivo a la invocación del pasado histórico y de la clandestinidad. Por tanto, a la búsqueda de una legitimidad y de un reconocimiento internacional se unió el deseo de homogeneizar a la base ugetista y socialista a través de unos recuerdos comunes que trascendiesen las discrepancias de los años treinta. No debe extrañar, pues, esa disociación de la memoria colectiva socialista respecto al período republicano con la excepción de la rectificación final en la guerra civil.

La exaltación de Pablo Iglesias fue continuada durante la transición para evitar la memoria histórica más conflictiva de los años treinta. Algo parecido ocurría respecto a la rememoración de las figuras de Largo Caballero y Besteiro. Sólo a partir de los años ochenta se produjo la recuperación de Azaña, frente a las anteriores visiones críticas del exilio, y de los hombres

26 Martínez Cobo, Carlos y José, 1944-1976. El Socialista. Madrid. Pablo Iglesias, 1984, págs. 63-64. 
de Estado Indalecio Prieto y Juan Negrín, considerados hasta entonces como personalidades socialdemócratas vinculadas, además, a la silenciada experiencia frentepopulista.

Esta continuidad simbólica socialista fue reforzada por la tendencia a la recuperación de las experiencias de todo el exilio y el antifranquismo. Hubo sin duda un realce de las experiencias de posguerra sobre la memoria histórica socialista del primer tercio de siglo. La política de la memoria del PSOE tendió a la recuperación de los contenidos de antifranquismo (exilio, represión, clandestinidad) sobre otras referencias históricas.

A modo de conclusión se puede decir que las dimensiones de la ideología y la cultura política refuerzan la interpretación de continuidad con la experiencia del exilio y, por tanto, de reestructuración más que refundación de las organizaciones socialistas durante la transición ${ }^{27}$.

27 Una justificación más amplia erı mis libros, E! PSOE contra Franco (Madrid, Ed. Pablo Iglesias, 1993), Las izquierdas españolas desde la guerra civil hasta 1982 (Madrid, UNED, 1997) y, sobre todo, Exilio y clandestinidad. La reconstrucción de UGT, 1939-1977, (Madrid, UNED, 2001). 